\section{Infrared Microspectroscopy And Computer Library Searching}

Kenneth Smith, Ph.D, Research Chemist McCrone Associates

In today's FTIR market, many instrument manufacturers provide software to perform searches of computer library spectra. With the increased speed of computers running FTIR instruments, you can have the result of a computer library search in literally seconds. However, as we rely more and more on computers in the laboratory we need to keep in mind the limitations and possible areas for error in these applications.

Computer library search programs calculate the difference between the sample spectrum and reference spectrum typically based on peak position and intensity. Different searching algorithms can stress one or the other. The result of a computer search is a Hit List with each hit having a hit quotient index (HQl) to indicate how close that particular spectrum matches the sample spectrum. In some programs the quotient which indicates an exact match would be 1 or 100 , in others it is 0 . The list of hits is essentially a list of suggestions. They can give you an indication of the type of material in the sample, but they do not typically identify the sample with a $100 \%$ match. On the $\mathrm{HQl}$ scale of 1 to 100 , we can be reasonably certain that if the $\mathrm{HQl}$ is below 50 we need to either do some more work to prepare a better sample or look at a different library. Generally, hits above 80 are in the ball park. Make sure you are searching a library which contains spectra of reasonably expected compounds. In some cases you may have several different libraries available to search. When given a choice of different algorithms, running a series of standards to test each one is often the best way to determine which one to use.

When the spectrum of a lab prepared sample of potassium sorbate was searched using the Hummel Polymer and Additives Library, using different algorithms, the results vary. The top four hits are listed below with their $\mathrm{HQI}$ from different algorithms.

\begin{tabular}{|c|c|c|c|c|}
\hline & $\begin{array}{l}\text { Square } \\
\text { Difference } \\
\text { Sum }\end{array}$ & $\begin{array}{l}\text { Absolute } \\
\text { Difference }\end{array}$ & $\begin{array}{l}\text { Euclidean } \\
\text { Distance }\end{array}$ & $\begin{array}{l}\text { Smocthed } \\
\text { Derivative } \\
\text { Correlation }\end{array}$ \\
\hline $\begin{array}{l}\text { Potassium } \\
\text { Sorbate }\end{array}$ & 99.99 & 99.86 & 99.77 & 88.99 \\
\hline $\begin{array}{l}\text { Sodium } \\
\text { Benzoate }\end{array}$ & 99.62 & 97.33 & 93.82 & 52.21 \\
\hline $\begin{array}{l}\text { Sebacic } \\
\text { Acid }\end{array}$ & 99,66 & 9733 & 94.13 & 48.04 \\
\hline Nitromethane & 99,59 & 96.93 & 93.60 & 46.22 \\
\hline
\end{tabular}

As you can see, different algorithms give different levels of discrimination. The data in the Smoothed Derivative Correlation column has a significant gap between the top answer and the next answer. This gap is often a good indication of an accurate search. In some cases the top three to five search results are grouped together, with relatively close HQl's. This typically indicates that the class of chemical has been identified but the specific type is not clear.

In all FTIR applications, good sample preparation is imperative to getting useful results. In FTIR microspectroscopy, sample preparation is even more important because the sample essentially becomes part of the optical system. This article is not specifically about sample preparation, but a brief description of things to watch out for is in order.

Sample inhomogeneity can be a problem in all types of infrared spectroscopy. In order to get useful information from a computer search, the sample spectrum should represent a reasonably pure material. Residual solvents (i.e. water, Nujol) can cause significant interferences in the spectrum. In small particle analysis it is often beneficial to sample the matrix a particle is supported in, or on, as well as the particle. The matrix spectrum can then be subtracted from the particle spectrum if necessary.

Sample thickness is a very important aspect in infrared microspectoscopy. In general, samples from 3 to 15 microns thick give good spectra for interpretation and searching. Because band intensities are a primary searching parameter, samples that are too thick can give misleading results.
An example of a sample spectrum of di-n-octyl phthalate which is too thick is shown in Figure 1. A computer search of this spectrum gave results which described the spectrum as a mixture of alkyd and triglycerides or alkyd and polyurethane. Thick samples can be useful for the interpretation of the smaller features in a spectrum, however computer searches of these types of samples do not often provide accurate information.

Other sample preparations can result in spectral features which can be misinterpreted by a search algorithm. If a solid sample is very flat and has parallel surfaces (e.g. a thin sample pressed between two salt plates) you may see the rolling baseline of an interference pattern from the IR radiation bouncing between the inner surfaces as shown in Figure 2. These features are strong enough to cause calculation errors when searching.

Another consideration regarding computer searching in infrared microspectroscopy is the library being searched. Most libraries available consist of spectra collected on regular FTIR instruments. Typically these libraries are very effective because they cover a wide variety of compounds. Many libraries are available which have library spectra of chemicals of a particular type such as ketones or adhesives. The best advice for library searching is to make your own libraries by collecting as many spectra as you can on your own instrument, of standards you have prepared yourself in a reproducible manner. Although this can be time consuming, the library spectra are typically more accurate since they were collected under the same conditions as your samples. And the library spectra you collect yourself will contain the spectra of chemicals you normally analyze.

To summarize, you need to remember that computer searching does not remove you from the interpretation of spectra. The list of hits are spectra which were determined mathematically to be close to the sample spectrum. You should use these as hints to make an accurate interpretation. Know what type of algorithm your search program uses. You may have several options to chose from. If little information is provided about the algorithms, test each one using a variety of different standards. Find out which gives the most reliable answers. Reproducible sample preparation using good sample preparation techniques will help your search be more accurate. Build you own libraries to search by collecting as many spectra of standards as possible. And finally, ask yourself "Does this result make sense?" when you examine the hit list. Accurate interpretation is ultimately the responsibility of the analyst.
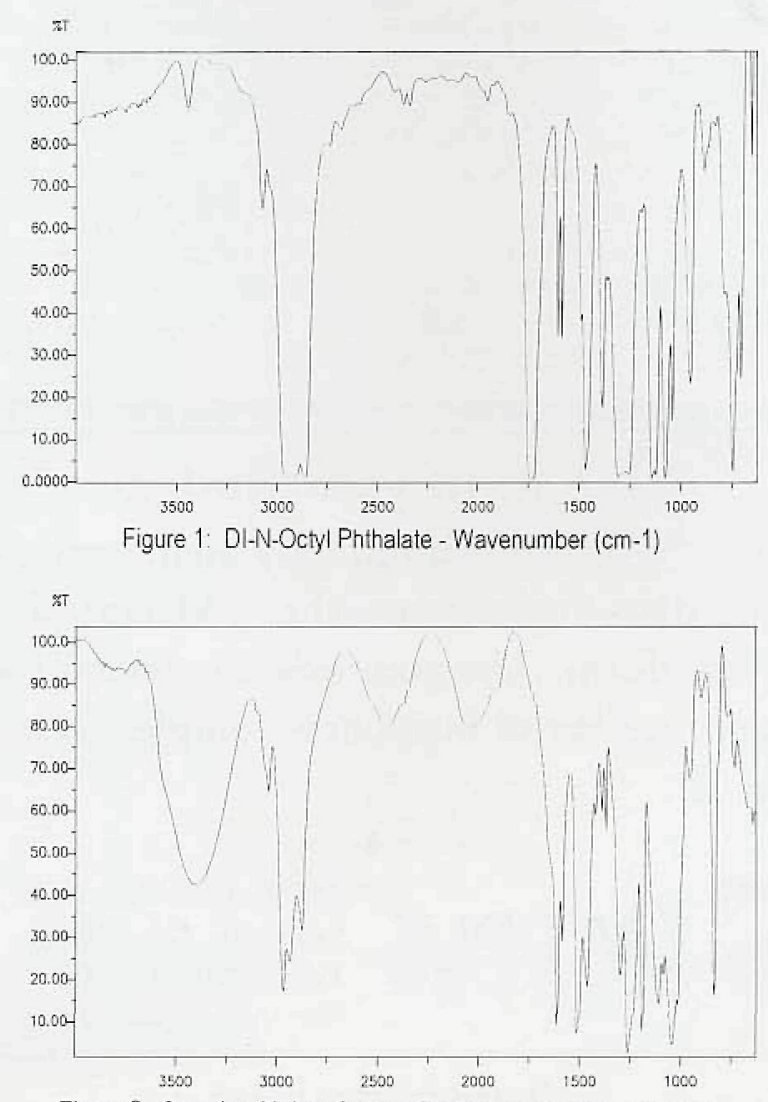

Figure 2: Sample with Interference Pattern - Wavenumber (cm-1) 
$\checkmark$ Sept 8/9 94: ImmuonGold Wet Workshop. Univ of Bristol. (31)-8370-97676 or Fax: (31)837015955

$\checkmark$ Sept 12/15 '94: MICRO 94 - International Microscopy and Image Analysis. London, UK. RMS (U.K.): (0865)248768 Fax: (0865)791237

$\checkmark$ Sept 21/23 94: Microscopy/Photomicrography Workshop. American Type Culture Collection. Rockville, MD. (301)231-5566.

$\checkmark$ Sept. 23/25 94: 13th Annual Symposium on Advances in Microscopy. NC Soc. for Microscopy and Microbeam Analysis. Wrightsville Beach, NC. Betty Gooch, Tel.: (919)684-3534.

$\checkmark$ Oct. 24/28 '94: 41st American Vacuum Society National Symposium. Denver, CO. Angela Mulligan: (212)248-0200.

$\checkmark$ Oct. 31/Nov. 2 '94: Scanning Probe Microscopy Applications to Semiconductor Materials and Devices. Industrial Associates Program, Arizona State Univ., Tempe, AZ. Lyseth Mitchell, Tel.: (602)965-7155, Fax: (602)965-1979. $\checkmark$ Nov. 15/17 94: Ultramicrotmoy for General Planar and Transverse Sectioning. Nov. 15/18 "94: Ultramicrotomy for Thin Section Preparation. NanoTEM, Scottsdale, AZ. Dr. F. Shaapur, Tel:: (602)759-2808.

$\checkmark$ Nov. 29/Dec. 1 '94: 94 Material Research Society (MRS) Fall Meeting. Boston, MA Mary Kaufold, Tel.: (412)367-3036, Fax: (412)367-4373

$\checkmark$ March 5/10 '95: PITTCON '95. New Orleans, LA. (412)825-3220, Fax: (412)825-3224

$\checkmark$ March 20/24\& 27/31 '95: Practical Aspects of Scanning Electron Microscopy. Univ. of MD Short Course. College Park, MD. Tim Maugel, Tel.: (301)405-6898, Fax: (301)3149358 .

$\checkmark$ March 28/31'95: SCANNING '95. Monterey, CA. Mary K. Sullivan: (201)818-1010, Fax: (201)818-0086. $\checkmark$ April 4/7 95: Uitramicrotomy in Materials Science. RMC. Tucson, AZ. Bob Chiovetti: Tel.: (602)889-7900, Fax: (602)741-2200.

$\checkmark$ June 12/22 '95: Lehigh Microscopy Courses - SEM, X-ray Analysis, AEM, AFM. Bethelem, PA. Prof. David B. Williams, Tel.: 610)758-5133, Fax: (610)758-4244

$\checkmark$ June 26/30 '95: Computer Simulation and Processing of HRTEM Images. NCEM, Lawrence Berkeley Lab., Berkeley, CA. Michael A. O'Keefe, eMail: MAOK@LBL.GOV.

$\checkmark$ August 6/11 '95: Microbeam Analysis Society (MAS) National Meeting. Breckenridge, CO. Gregory Meeker, Tel.: (303)236-1081, Fax: (303)236-1414.

$\checkmark$ Oct. 12/14 '95: GLEMA '95. Toledo, $\mathrm{OH}$ Carol A. Heckman, Tel.: (419)372-2432 D

\section{Notes to our readers:}

1) We remain very interested in expanding our mailing list - to those who actually wish to receive no cost copies. To this end, we would greatly appre. ciate your forwarding a copy of the newstetter to others with an interest in any facet of microscopy. Many thanks!

2) We are also very interested in improving each mailing address as much as possible. Would you please check your address on this issue and advise should there be improvements.

I should mention that we do not have "control" over the extended zipcode. U.S. Postal Service ap. proved software assigns zipcodes dependent upon the balance of the address.

Should there not be the 4. digit extension to your zipcoile, USPS "says" that the street address we are using, if any, is not valid. Wedounderstand that several establishmenty do not either know or use their USPS assigned street addresses.

3) We hope that you are finding issue content to be improving with each issuel our toughest chat lenge remains to obtain anticles and material of real value. White articles of any length are appreciated, we particularly value short ones. And the oniy criteria is that the topics be of interest to a reasonable number of working microscopists. We would greatiy appreciate your assistance in mak. ing this publication of value.

Don Grimes

\section{Notes to our advertisers:}

Do you receive publications in the mail which go directily into the "circular file"? If so, have you thought that some advertiser had (indirectly) paid for the paper, printing and postage. And - have you considered the number of issues that never make it to a reader due to an incorrect address? With these thoughts in mind, and rather than trying to impress you with the "size" of our maiting list, we are now maiting only to those who have requested a copy - and have substantially reduced our advertising prices. For example.

1) Price for a full color, full page ad, with a $5 x$ discount, is now $\$ 1,305.00$.

2) Price for a black only, eighth page ad, with a 5 $x$ discount, is now $\$ 270.00$.

And, as an "exmanufacturer", I would like to provide a means where a new (or umproved) product could be presented to my readers - cheaply! In our next issue, we with have a "New Product News" section. Concept will be a haif-page column ( $35 / 8$ "wide) with text priced a dollar per word. Also - with this issue yow will note an improved reader response card system.

Kindily contact me if you would like a copy of our new rate sheet.

\section{- Don Grimes}

